\title{
Educação intercultural indígena: reflexões no contexto escolar Terena da aldeia Ekeruá
}

\author{
Intercultural indigenous education: reflections in the Terena village Ekeruá school context \\ Educación intercultural indígena: reflexiones desde el contexto escolar Terena Ekeruá

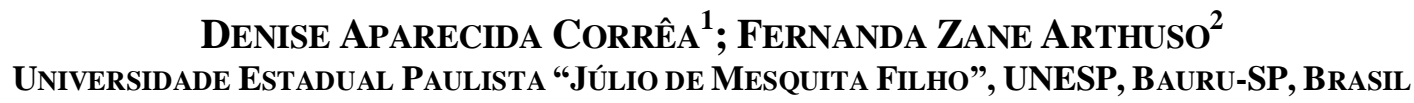

\section{RESUMO}

Este artigo tem por objetivo trazer reflexões acerca da educação intercultural a partir dos processos educativos da Escola Estadual Indígena da Aldeia Ekeruá. A pesquisa pautada na abordagem qualitativa do tipo etnográfica se configurou na análise dos registros de diários de campo e dos depoimentos de dois interlocutores da Escola Estadual Aldeia Ekeruá. Consideramos que no contexto da Aldeia Ekeruá a Escola é lócus de preservação identitária Terena: de sua língua materna, de suas histórias, de suas danças, de seus jogos, de seus rituais e é também um espaço importante de apropriação da perspectiva ocidental de conhecimento e de obtenção de instrumentos para a leitura desta outra epistemologia. Assim, na imbricada e tensa rede de relações que tecem cotidianamente com a sociedade e o conhecimento ocidental, a escola é o lugar no qual tais conhecimentos são ressignificados a partir da epistemologia indígena Terena, é, portanto, tempo-espaço de interconhecimento, de educação intercultural.

Palavras-chave: Educação Intercultural. Escola Indígena. Terena.

\begin{abstract}
This article aims to bring reflections about intercultural education from the educational processes of the State School Indigenous Ekeruá Village. The research based on the qualitative approach of the ethnographic type was configured in the analysis of the records of field diaries and the testimonies of two interlocutors of the Ekeruá Village State School. We consider that in the context of the Ekeruá Village, the School is a locus of identity preservation Terena: of its mother tongue, its stories, its dances, its games, its rituals and is also an important space of appropriation of the western perspective knowledge and instruments for reading this world. Thus, in the imbricated and tense network of relationships that weave everyday with society and western knowledge, school is the place in which such another epistemology is re-signified from the Terena indigenous epistemology, is therefore time-space of inter-knowledge, education intercultural.
\end{abstract}

Keywords: Intercultural Education. Indigenous School. Terena.

\section{RESUMEN}

Este artículo tiene por objetivo traer reflexiones acerca de la educación intercultural a partir de los procesos educativos de la Escuela Estadual Indígena de la Aldea Ekeruá. La investigación pautada en el abordaje cualitativo del tipo etnográfico se configuró en el análisis de los registros de diarios de campo y de entrevistas de dos interlocutores de la Escuela Estadual Aldea Ekeruá. Consideramos que en el contexto de la Aldea Ekeruá la Escuela es locus de preservación de la identidad Terena: de su lengua materna, de sus historias, de sus danzas, de sus juegos, de sus rituales y es también un espacio importante de apropiación de la perspectiva occidental de obtención de instrumentos para la lectura de esta otra epistemología. Así, en la imbricada y tensa red de relaciones que tejen cotidianamente con la sociedad y el conocimiento occidental, la escuela es el lugar en el cual tales conocimientos son resignificados a partir de los conocimientos indígenas Terena, es, por lo tanto, tiempoespacio de inter-conocimiento, de educación intercultural.

Palabras clave: Educación Intercultural. Escuela Indígena. Terena.

\footnotetext{
${ }^{1}$ Professora Assistente do Departamento de Educação Física da UNESP Bauru. E-mail: decorrea@ @c.unesp.br 2 Mestra em Psicologia do Desenvolvimento e Aprendizagem pela UNESP Bauru. E-mail: fer_rcm@hotmail.com
} 


\section{INTRODUÇÃO}

O título deste artigo enseja o paradoxo que nos propomos discutir: traz à cena a Escola - instituição consagrada pela transmissão e perpetuação do pensamento eurocêntrico - e uma Aldeia Indígena - lugar de resistência à opressão da colonialidade europeia ${ }^{3}$.

A história do Brasil, até hoje apresentada e contada na escola eurocentrada tanto pelos seus professores, quanto pelos livros didáticos, revela em seu enunciado o ponto de vista do dominador invocando a sua descoberta. O termo descobrimento do Brasil ignora os habitantes que aqui viviam, afinal, segundo Luciano (2006, p.17) no atualmente denominado território brasileiro "[...] habitavam pelo menos 5 milhões de pessoas, por ocasião da chegada de Pedro Álvares Cabral, no ano de 1500. Se hoje esse contingente populacional está reduzido a pouco mais de 700.000 pessoas, muitas coisas ruins as atingiram". Vale dizer que se tratou, portanto, não de uma descoberta de tal território, mas de uma invasão (GONÇALVES JUNIOR, 2010).

A violência de tal invasão europeia se impôs de um lado pelo massacre e extermínio, marcadamente o genocídio ${ }^{4}$ das populações indígenas e, de outro, através de um dos pilares da dominação, o epistemicídio, com a supressão do arcabouço de experiências e de conhecimentos desses povos, pois não atendiam ou até contrariavam aos interesses e propósitos da invasão.

Com isso, desperdiçou-se muita experiência social e reduziu-se a diversidade epistemológica cultural e política do mundo. Na medida em que sobreviveram, essas experiências foram submetidas à norma epistemológica dominante: foram definidas (e, muitas vezes, acabaram-se autodefinindo) como saberes locais e contextuais (SANTOS; MENESES, 2010, p.17).

O epistemicídio se revela na educação escolarizada empreendida pelo projeto de colonização, que atuou com o propósito de aniquilar os saberes do mundo-vida indígenas, munindo-se, de regimes de clausura. A exemplo de outras ordens religiosas, os missionários salesianos implantaram as Escolas-Internato nas aldeias existentes no Alto Rio Negro, como relata Luciano (2011, p. 74) com a propriedade de quem viveu dez anos em uma dessas escolas:

Ao isolar as crianças e os jovens indígenas do convívio de seus familiares e de suas comunidades, as escolas-internato pretendiam inculcar os novos padrões de cultura e de comportamento dos colonizadores e ao mesmo tempo fazê-los desprezar e esquecer as tradições e costumes.

A narrativa acerca da implantação da educação escolarizada por missionários religiosos entre os indígenas Guarani Kaiowá, também revela os procedimentos coercitivos adotados frente à resistência manifestada pelas famílias e pelas crianças em permanecer na escola, como menciona Benites (2009, p.74):

O modelo educacional foi implementado sempre tentando se impor o modo de viver e de educar do povo ocidental, isto é, introduzindo noções de

\footnotetext{
3 A expressão "Colonialidade" se refere à imanência e a permanência duradoura da dominação e exploração, as quais, os mais de 240 povos indígenas brasileiros, resistem e sobrevivem até os dias atuais (QUIJANO, 2010).

${ }^{4} \mathrm{O}$ estudo de Will (2014) mostra que as práticas de extermínio dos povos indígenas brasileiros para a invasão e ocupação de suas terras pela Coroa Portuguesa, se configurou como uma "política genocida de Estado" com flagrantes interesses mercantis.
} 
higiene, vestimenta, hábitos comportamentais, regras de organização da vida escolar e crenças religiosas, desrespeitando as tradições de conhecimento e os métodos educativos próprios dos indígenas. Tal modo de proceder acabou frustrando os desejos de ler e escrever dos Kaiowá.

Essa é a escola que a população brasileira, indígena e não indígena herdou, cujos conteúdos curriculares, a metodologia das aulas ministradas, bem como, o conteúdo do acervo didático, se constituíram na forma bem-sucedida de transmitir e perpetuar a crença de que há um conhecimento reconhecidamente válido, único e que se postula ser verdadeiro, cuja edificação e posse têm sua origem na sociedade ocidental e em um lugar específico do mundo: a Europa.

Evidentemente, não se trata de, na radicalidade das posições, adotar uma abordagem ingênua e fazer uma apologia contra a Europa e os Europeus, pois compreendemos com Quijano (2010, p. 86) que:

\begin{abstract}
O eurocentrismo não é, exclusivamente, portanto a perspectiva cognitiva dos europeus, ou apenas dos dominantes do capitalismo mundial, mas também do conjunto dos educados sob sua hegemonia [...] Trata-se da perspectiva cognitiva do longo tempo do conjunto do mundo eurocentrado do capitalismo/colonial/moderno e que naturaliza a experiência dos indivíduos nesse padrão de poder. Ou seja, fá-las entender como naturais, como consequentemente dadas, não suscetíveis de serem questionadas.
\end{abstract}

Assim, nos interessa buscar conhecer e apreender com as Escolas em contexto Indígena, as quais são representativas da resistência à dominação e opressão e, sobretudo, da luta ao direito a uma Escola que atenda suas particularidades e suas necessidades.

O presente artigo resulta das incursões realizadas em uma aldeia indígena Terena pertencente à Terra Indígena Araribá, uma reserva localizada na cidade de Avaí, no Estado de São Paulo, Brasil. O objetivo principal é trazer reflexões acerca da educação intercultural a partir dos processos educativos da Escola Estadual Indígena da Aldeia Ekeruá.

O caminho metodológico percorrido teve referencial teórico metodológico pautado na abordagem qualitativa do tipo etnográfica (ANDRÉ, 1995). A incursão na comunidade se estabeleceu com um convívio semanal ao longo de um período de cinco meses, cujos encontros foram registrados em diários de campo, ou seja, relatos escritos dos acontecimentos e diálogos com as/os interlocutoras/es (BOGDAN; BIKLEN, 1994).

Posteriormente a cada relato foi realizada uma reflexão sobre os dados, com o objetivo de aprimorar os diários de campo. Nesse processo de releituras dos diários, percebemos a necessidade de realizar entrevistas de aprofundamento com membros da comunidade, a fim de desvelar pontos relevantes para compreensão do fenômeno interrogado nos diários.

Os diálogos com os membros da comunidade, seja por meio de entrevistas ou registrados em diários de campo, aparecem devidamente identificados nos excertos, mantendo a identificação nominal sob sigilo, atendendo aos preceitos éticos.

\title{
O CHÃO QUE PISAMOS: A ESCOLA E O CONHECIMENTO INDÍGENA NO SISTEMA MUNDO COLONIAL CAPITALISTA GLOBALIZADO
}


"A maior contribuição dos indígenas ao Brasil é ainda estarmos vivos",

Estas foram as palavras de Daniel Munduruku (2013), indígena que carrega o nome de seu povo, ao ser questionado sobre qual a contribuição dos indígenas para o país. Sua resposta simples, honesta profunda provoca e invoca questões bastante profundas e dolorosas, de uma história marcada pela exploração e dominação.

Nesse percurso, o discurso dominante e hegemônico, perpetuou a ideia de que o único conhecimento existente e válido é aquele construído pelos europeus, sobrepostos a todos os outros conhecimentos que tenham sua origem fora do Ocidente, os quais são considerados, no máximo, conhecimentos "folclóricos".

A expressão folclorizar se refere a, por exemplo, transformar a profundidade das histórias contadas por cada nação indígena, as quais trazem, pela própria natureza cultural diversificada de cada etnia, uma multiplicidade de cosmovisões, de forma pejorativa a partir dos termos "mitos" e "lendas". Tratados desta maneira, tais conhecimentos para além de inferiorizados, são invisibilizados, ou nas palavras de Santos (2010, p.102), são produzidos como inexistentes: "Há produção de nãoexistência sempre que uma dada entidade é desqualificada e tornada invisível, ininteligível ou descartável de um modo irreversível".

Neste sentido, o sistema escolarizante que criticamos, tem privilegiado o conhecimento de matriz ocidental e europeia, em detrimento de outros tantos saberes não ocidentais, oriundos da diversidade de povos e nações indígenas, o que no contexto brasileiro, atuou em duplo sentido: não só contribuiu para apagar e anular formas de compreender o mundo e produzir experiências de povos originários indígenas, como também negou a possibilidade da visão e versão eurocêntrica de mundo e da história serem questionadas e confrontadas, e assim, possibilitar que "[...] as experiências produzidas como ausentes sejam liberadas dessas relações de produção e, por essa via, se tornem presentes" (SANTOS, 2010, p.104).

Este processo foi tão bem sucedido que o exemplo mais claro para nós é a perpetuação de uma "representação" das nações indígenas, assentada no indígena como caricatura ou ilustração, cuja imagem estereotipada de andarem nus e com cocar na cabeça, ainda prevalece e, portanto aqueles que não se enquadram nesta construção simbólica propagada inclusive pelos livros didáticos escolares, não são indígenas. É muito comum encontrar relatos, inclusive no meio acadêmico, convictos de que os indígenas foram todos exterminados e de que não há mais indígenas "puros". Como consequência da crença de que não existem mais povos indígenas no Brasil, se promove outro apagamento do indígena como pessoa que tem cosmovisões e demandas por existência, com intenção clara de desconfiguração e desmoralização das suas lutas por tais demandas.

Interessante observar a fala ${ }^{6}$ do militante indígena dos direitos humanos Ailton Krenak, que ao narrar as lutas nas quais se engajou para assegurar território em um lugar cercado por pecuaristas e para sobreviver diante da ameaça da ferrovia da Companhia Vale do Rio Doce, nos ensina como expressões adotadas no campo jurídico e das legislações também atuam de modo a desfigurar a legitimidade dos povos

\footnotetext{
${ }^{5}$ Por ocasião do ciclo de Práticas Educativas "Culturas afro e indígenas e suas contribuições para o desenvolvimento humano" e "Vivenciando a arte indigena brasileira" realizado entre os dias 22 e 23 de março de 2013 no SESC-SP na cidade de Bauru, Estado de São Paulo, Brasil.

${ }^{6}$ Por ocasião do Seminário "Em busca de uma Terra sem tantos males: o Watu, o crime ambiental e a teia da Vida", realizado em 16 de março de 2016, no Centro de Estudos Sociais da Universidade de Coimbra (CES/UC), Portugal.
} 
indígenas enquanto um grupo social. Comenta que a expressão "territorialidade", compreendida pelos indígenas como representação de uma identidade, gradualmente foi substituída por termos que segundo ele, esvaziam a representação de um coletivo e do pertencimento identitário dos indígenas à terra que para eles está no campo do sagrado, cuja compreensão é "[...] herança comum de uma tribo" (KRENAK, 2016).

Ailton Krenak chama nossa atenção dizendo que todos nós estamos ameaçados diante da prática conjugada da tríade Governos Regionais - Corporações - Mercado, cujo projeto avassalador torna justificável e legalizado a exploração econômica dos recursos naturais, os quais são tratados como verdadeiros "Almoxarifados" para as grandes Corporações, que podem se apropriar e explorar ao máximo suas riquezas e depois abandonar quando se esgotar. Para ele, o Rio Watú, como é conhecido o Rio Doce pelos Krenak, "[...] é uma entidade, um Ser, por isso não pode ter um dono" (KRENAK, 2016).

As lógicas mercantilistas subvertem essa compreensão e, interessante como sua fala nos atenta para as mensagens subliminares aparentemente inofensivas que as sustentam, citando o exemplo do crime cometido por uma multinacional, o qual teve ampla repercussão pela dimensão catastrófica ambiental, bem como, trágica para a população de inúmeras cidades atingidas e que nos pronunciamentos e entrevistas coletivas dadas ao público, as autoridades governamentais e os representantes da multinacional, se referiam ao Rio como "morto" e, nesta condição, implicitamente está a constatação de que não se justifica qualquer investimento. E em oposição e crítica, o fotógrafo Sebastião Salgado, se referiu ao estado do Rio Watú como "em coma", mas não morto (KRENAK, 2016).

Assim as falas de Daniel Munduruku e Ailton Krenak tem a profundidade de nos despertar, enquanto seres situados e históricos, para a constatação de que fomos e somos todos colonizados. A esperança está nas lutas dos povos indígenas e pelo seu modo de vida, e graças às quais temos ainda por que e por quem lutarmos em um mundo no qual tudo se mercantiliza, a Vida vale menos que os interesses do Mercado, inclusive daqueles que lutam pela Vida de todos e todas ${ }^{7}$.

Por isso é urgente que não indígenas tomem a luta dos indígenas como sua, qualquer que seja seu campo de atuação, para em um movimento contra hegemônico fazer insurgir, práticas sociais cujos processos educativos se legitimem em formas de conhecimentos diferentes e autossuficientes para determinado contexto. A emersão de outros saberes pautados em critérios de rigor que não aqueles outorgados pelo cânone científico, mas que operam com credibilidade nos contextos sociais em que são produzidos têm por esta condição, a potência de se colocar como saberes legítimos, sob o pressuposto de que não há saber universal, a ponto de dar conta de responder a complexidade da diversidade de experiências. Tampouco a ausência do saber científico nos coloca órfãos de saberes ou em completa ignorância, pois "Toda ignorância é ignorante de um certo saber e todo saber é a superação de uma ignorância particular" (SANTOS, 2010, p. 106).

Como assinala o autor, deste princípio de incompletude dos saberes, se deduz a possibilidade de diálogo e confrontação entre saberes diferentes, cujo cerne é a possibilidade de serem confrontados e dialogados como cada saber orienta uma determinada prática para superar uma ignorância em particular.

\footnotetext{
${ }^{7}$ Assinalamos o extermínio de inúmeras lideranças indígenas ou defensores de suas causas na América Latina, que temos assistido nas últimas décadas, o brasileiro Francisco Mendes Filho, o Chico Mendes, líder sindicalista seringueiro, morto em 22 de dezembro de 1988; o líder Guarani-Kaiowá, Semião Vilhalva, assassinado por fazendeiros devido ao conflito de terra em 29 de Setembro de 2015 e Berta Isabel Cáceres Flores, líder indígena hondurenha do povo Lenca, assassinada em 03 de março de 2016.
} 
Este é o "chão que pisamos" e no qual situamos nossas reflexões acerca da Escola Indígena, cientes de que também é nesta trajetória de sacrifícios e de lutas para recuperar ou evitar mais perdas (da terra, do modo de vida, da língua) que encontramos a história dos indígenas Terena da Aldeia Ekeruá, dentro da Reserva Terra Indígena Araribá, no Estado de São Paulo e que nos permitiu "conviver para aprender", com o gesto silencioso e generoso, de nos acolher, percurso que delineamos a seguir.

\title{
O povo Terena e A Aldeia EKERUÁ - UM PERCURSo deSDe nOSSA IGNORÂNCia OCIDENTAL
}

Em conversas com os moradores de Ekeruá, não foram poucos os relatos de situações vividas por eles, em que enfrentaram o desconhecimento, o preconceito e a discriminação da sociedade "não índia", como descrevemos a seguir, iniciando com o trecho do diário de campo que relata nossa conversa com o nosso primeiro interlocutor na Aldeia, o professor de Matemática da Escola Estadual Aldeia Ekeruá, o qual:

\begin{abstract}
[...] nos contou da falsa construção que muitas pessoas fazem sobre os índios. Comentou de uma vez que saiu da aldeia para um evento na cidade, ele foi com seu cocar e uma criança ficou com medo dele. Ele disse a ela que não precisava ter medo de índio, e então o pai da criança explicou que era porque seu filho assistia muito desenho do Pica-Pau, e nesse desenho tem um índio que bate no Pica-Pau, por isso a criança estava com medo. Outra falsa imagem é o barulho que é feito com a boca que muitos acham que os índios fazem, mas os índios dessa região não fazem isso, eles nem sabem o que isso quer dizer e que muitas vezes as crianças da aldeia fazem isso, mas imitando os não índios, pois acham que eles fazem esse barulho, batendo a mão na boca (Diário de Campo, 29 de agosto de 2012).
\end{abstract}

Outro relato foi o do professor de Língua Portuguesa, que em um momento de curiosidade perguntou se havia interesse dos estudantes não indígenas na Universidade em realizar pesquisas com indígenas e comentou que nosso trabalho "[...] será muito importante para mudar a opinião das pessoas sobre os índios", foi quando nos narrou a seguinte situação:

\begin{abstract}
Fui ao mercado e quando fui passar pelo caixa a mulher que estava lá não aceitava meu dinheiro, dizia que o que eu tinha não era dinheiro. Respondia que era sim, que eu havia acabado de tirar do banco e que o homem que estava na minha frente na fila passou com o mesmo dinheiro sem nenhum problema. Comecei a falar para ela que ela estava sendo preconceituosa só porque eu não era de lá. Perguntei a ela se ela sabia que preconceito é crime e que se quisesse poderia denunciá-la, mas que ela deu sorte de eu ser bom e de não ter feito isso com alguém mais agressivo que eu. Disse a ela para que isso servisse de lição. E então ela ficou sem graça e aceitou meu dinheiro (Diário de Campo, 26 de março de 2012).
\end{abstract}

A história da constituição da reserva Terra Indígena Araribá, nos possibilitou perceber que o modo de vida daquele povo e parte importante da sua cultura tiveram que ser suprimidos para que pudessem sobreviver ali, como nos contou o professor de Matemática:

[...] muitos visitantes que vão à aldeia perguntam se não tem ocas por lá; se eles não caçam para sobreviver. E fez uma importante observação: que não há floresta ao redor da aldeia, já que ali, quando chegaram era um grande pasto. Todas as árvores que ali estão foram plantadas por eles, toda a 
vegetação, inclusive a que protege o Rio Batalha de assoreamento. Disse também que eles moram perto das cidades e, portanto, tiveram que se adequar ao modo de vida urbano (Diário de Campo, 29 de agosto de 2012).

A Aldeia está localizada próxima a uma cidade de porte médio (40 km de BauruSP) e a ausência de mata no perímetro da Aldeia, fez com que tivessem que se adaptar ao modo de vida urbano, buscando rendimentos para aquisição de alimentos, já que não tinham como plantar ou pescar, por isso a busca por remuneração em trabalhos assalariados fora da aldeia, não foi, inicialmente, uma opção, mas uma necessidade.

O professor de Matemática também nos contou que:

[...] seus antepassados ao chegarem nessas terras, lhes foi prometido a construção de casas com as madeiras das árvores que haviam sido cortadas naquele território, porém, a madeira foi comercializada e nenhuma casa construída, ocasião em que tiveram que construir casas de alvenaria (Diário de Campo, 29 de agosto de 2012).

Casas nas quais, inclusive, foi difícil adaptarem-se como percebemos no relato do professor de Oficina:

[...] sobre a mudança das casas de sapé para as de alvenaria, ficou claro que ele preferia casas de sapé, pois as considerava mais confortáveis, disse que a parede de barro mantém a casa mais fresca no calor e no frio a mantém aquecida. Acredita que essas casas são mais seguras que a de alvenaria, pois quando tem vento forte o sapé não sai, diferente das telhas, e também disse que não chove dentro (Diário de Campo, 29 de agosto de 2012).

Tais conhecimentos acerca da construção das casas, muito eficientes e sustentáveis além de essenciais para a sobrevivência do Povo Terena, não foram considerados por ocasião da criação da Aldeia e continuam a ser suprimidos pelos arquitetos e engenheiros não indígenas, uma vez que, com o crescimento populacional na Aldeia, os mesmos reivindicaram o direito a fazerem jus a verbas de um projeto habitacional do governo federal e as casas que estão sendo construídas são todas em alvenaria e de padrão urbano.

Em uma das aulas de Oficina, o professor contou às crianças a origem do povo Terena e aprendemos com ele que os Terenas:

[...] vieram da fronteira da Bolívia com Paraguai e foram para o Mato Grosso do Sul, no entanto, ao atravessar o rio Paraguai, muitos índios morreram. Antigamente existiam cerca de trinta mil índios Terena na região de BuritiMS e Miranda-MS, mas hoje esse número diminuiu bastante ${ }^{8}$ (Diário de Campo, 14 de maio de 2012).

Segundo relatos de membros da comunidade, muitos vieram para a região de Avaí-SP para trabalhar nas lavouras ou porque se casaram com indígenas que já habitavam a região.

O município de Avaí-SP possui em seu território quatro Aldeias indígenas (Ekeruá, Kopenoty, Tereguá e Nimuendaju) em uma área denominada de Terra

\footnotetext{
${ }^{8}$ No ano de 2001 foram estimados dezesseis mil indígenas Terena vivendo em diferentes regiões do Brasil, no Estado de Mato Grosso do Sul, em nove municípios: Anastácio, Aquidauana, Dois Irmãos do Buriti, Miranda, Nioaque, Rochedo, Sidrolândia, em Porto Murtinho na Terra Indígena Kadiweu, Dourados na Terra Indígena Guarani e no Estado de São Paulo no município de Avaí, na Terra Indígena Araribá (ISA, 2014).
} 
Indígena Araribá, povoada por Terenas e Guaranis. A Aldeia Ekeruá existe há dez anos e é povoada por indígenas da nação Terena.

Atualmente, a Aldeia Ekeruá é composta por 27 famílias que moram em casas de alvenaria, dispostas em um grande círculo, onde no centro há um quiosque de sapé e duas grandes construções em formato circular similares ao quiosque. Uma delas é a casa de artesanato da Aldeia, a outra é a Escola Estadual Indígena Aldeia Ekeruá. No centro da Aldeia também encontramos um pátio comunitário, um campo de futebol e uma capela.

A aldeia utiliza a Língua Materna Terena e também a Língua Portuguesa, enquanto que os mais velhos falam exclusivamente a Língua Terena e compreendem algumas palavras em português. Há um esforço dos mais velhos e dos professores e professoras da Escola em mobilizar as crianças e os adolescentes a aprenderem e se comunicarem com a Língua Materna Terena, porém, a invasão cultural e, principalmente, a Televisão foi apontada como entrave, uma vez que interfere na convivência familiar, momentos em que os mais jovens aprendiam com os mais velhos, como relembra o professor de Matemática:

Eu sempre conversei com meu vô, muita coisa que eu sei hoje, a respeito de árvore, histórias que contava, que hoje eu falo, hoje eu sei por que ele me ensinou. Ia lá perguntava, assistia, mas assistia pouco TV. Tinha TV, mas era pouco que eu assistia. Hoje assiste mais, eu acho que toda casa tem televisão, então hoje não tem quase mais o momento de conversa, é difícil ter, mais tem ainda. Às vezes eu vou para a casa do pai e está todo mundo assistindo televisão, ou está fazendo artesanato, que são artesões, às vezes estão sentados né conversando, mas é difícil (depoimento gravado na Aldeia Ekeruá em 31 de julho de 2012).

Interessante perceber na trajetória de constituição das Escolas em aldeias indígenas, que para os Guarani Kaiowá na década de 1970, a Escola era uma aspiração para concretização do desejo de fazer "o papel falar":

[...] as lideranças de cada família começaram a discutir e pensar que seus membros mais jovens deveriam aprender a ler e escrever mesmo, justamente para desvendar a fala, os significados e saberes do não-índio, que se encontravam impregnadas no papel. Desse modo, as famílias Kaiowá passaram a interpretar que aprender a ler e escrever seria também um modo de poder sagrado (karai vera arandu), além de um instrumento valioso no contato com os karai, na relação de trabalho (changa), em transações comerciais, para não serem mais enganados (pono je hose) (BENITES, 2009, p. 76).

Na Aldeia Ekeruá, percebemos que a Escola é o lugar em que se projeta o movimento contrário: possibilitar às gerações que já dominam a língua do não indígena, se apropriarem da língua materna Terena, porque sabem que assim conservam sua identidade e, desta forma se fortalecem enquanto grupo étnico, como enfatiza o vicediretor da Escola que nasceu na Terra Indígena Araribá:

\footnotetext{
A hora que acabar sua língua, sua dança, aí não vai ter mais índio [...] hoje eu vejo da parte dos jovens que eles querem usar cocar bonito, para parecer que é índio mesmo. Mas não é... antigamente quando nós dançava o Bate-Pau nosso cocar era feito de papelão. Era de papelão e tinha uns enfeites desse papel de seda. Mas nunca ninguém falou assim "você não é índio", por quê? Porque todo mundo era falante [...] Quem prova que eu sou índio é o conhecimento que eu tenho pela história Terena e a linguagem. Quem que vai
} 
duvidar disso né? (depoimento gravado na Aldeia Ekeruá em 31 de julho de 2012).

Essas são as vozes que ecoam das comunidades indígenas e, situadas em seus contextos, em suas histórias, em seu mundo-vida nos convida à escuta atenta e nos convoca ao exercício ético solidário de pensar os povos indígenas para além da posição subalterna de povo colonizado; pensar as práticas sociais e as relações interculturais para além da relação dominante-dominado; pensar a Escola em contexto indígena para além da Escola eurocêntrica ocidentalizada.

\section{A Escola Estadual Indígena Aldeia EKERUÁ - uMA INCURSÃo PARA DESPOJAR NOSSA ARROGÂNCIA OCIDENTAL}

A Escola Estadual Indígena Aldeia Ekeruá pertence à Rede Pública Estadual de São Paulo e é vinculada à Diretoria Regional de Ensino de Bauru, caracterizada como intercultural, diferenciada, bilíngue (idiomas Terena e Português), na qual todos/as os/as professores/as, bem como o vice-diretor são indígenas moradores da Aldeia. A única função exercida por não indígenas é a direção da escola, a qual é designada pela citada Diretoria Regional de Ensino. À época de nossa inserção, percebemos que a relação era de muito diálogo e respeito por parte da então diretora, no entanto, acreditamos que os próprios indígenas poderiam e deveriam assumir plenamente a gestão da Escola, como inclusive prevê o que a legislação denomina como uma das características dessas escolas: ser comunitária, ou seja, "[...] conduzida pela comunidade indígena, de acordo com seus projetos, suas concepções e seus princípios" (BRASIL, 1998, p. 24).

Um aspecto a ressaltar é a educação indígena ser proclamada intercultural. Essa expressão tem tido ressonância na América Latina, especialmente ao tratar dos contatos com os povos originários em territórios invadidos e colonizados por povos europeus. Em uma perspectiva crítica, o discurso intercultural, assumido como o diálogo entre culturas, baseado no respeito e reconhecimento de suas diferenças, é, em suma um discurso ingênuo que omite os conflitos, as relações desiguais de poder, bem como, os efeitos do colonialismo e do capitalismo. Revestido de uma pretensa relação igualitária, mas que continua a serviço da ideologia homogeneizante, visando perpetuar a dominação, formulado hierarquicamente a partir do ocidente, tendo essa referência como matriz, em detrimento das experiências, referências e expectativas dos povos indígenas ${ }^{9}$.

As reflexões a partir do contexto escolar indígena da Aldeia Ekeruá, ajudam a compreender como o que está previsto na legislação, assume uma dinâmica não linear, porque aquilo que consideramos avanços na sociedade não indígena pode representar verdadeiros retrocessos se observarmos as práticas educativas indígenas.

Percebemos um sentimento ambíguo dessa comunidade com relação à educação escolarizada, pois se de um lado ela é uma aspiração e um imperativo para a autonomia em relação à sociedade não indígena, há a preocupação constante em zelar para, ainda que se apropriem da educação escolarizada, "não deixem de ser índio", como expressa o vice-diretor da escola:

\footnotetext{
${ }^{9}$ Para aprofundamento, ver as críticas de Menares (2014) a partir do contexto indígena Mapuche (Chile) e de Pérez (2014) a partir de investigação com jovens Aymara da província de Moho na região de Puno (Peru).
} 
O índio poder trabalhar, caminhar com as próprias pernas, andar sozinho. Ter um índio advogado, um doutor, né? Porque eu vou chegar e falar para ele... “eu estou com essa necessidade aqui” Então esse é o sonho... Mas por outro lado tem uma preocupação também né, porque a gente pode deixar de viver, não ser índio. Porque acaba a cultura né, não vai querer dançar mais, não vai defender seu povo, aí passa a gostar das coisas que não é nossa, passa a querer a ter um carro bom, roupa boa, querer morar lá fora, achar que lá que é melhor. Então a gente está com um pé na frente e outro atrás (depoimento gravado na Aldeia Ekeruá em 31 de julho de 2012).

Esse receio é legítimo na medida em que eles/as sentem as marcas profundas da herança do ensino escolarizado, e sabem que as mudanças nas leis nem sempre são acompanhadas da mudança de paradigmas, tanto nos sistemas de visão de mundo como no campo didático pedagógico, que envolve metodologias, infraestrutura e formação/contratação de professores/as indígenas, com a devida incorporação (salários e planos de carreira) no quadro de docentes do magistério público.

Com relação a este último aspecto, há uma luta muito antiga para que a educação escolar indígena seja feita exclusivamente por professores/as indígenas, porém, a contratação de professores indígenas e, principalmente a formalização como carreira não é uma realidade para todos os povos indígenas no território brasileiro, como destaca Fernandes (2010, p. 82):

No estado do Pará a formação de professores indígenas, bem como a realização de concursos públicos para carreira de magistério indígena parece estar longe de se tornar realidade. Na região do Xingu, relatos de lideranças informam que não há professores indígenas atuando nas escolas que oferecem apenas a primeira etapa do ensino fundamental e não há ensino médio regular nas aldeias. Os alunos indígenas são obrigados a saírem das aldeias para concluir a escolarização básica [...] Sem condições financeiras para custear os estudos na cidade, a maioria dos estudantes indígenas acabam abandonando os estudos.

Embora hoje a escola em Ekeruá tenha seu quadro exclusivamente formado por professores e professoras indígenas da comunidade, o que foi conquistado com muito esforço pessoal já que tinham que se deslocar da Aldeia e permanecer durante meses na Universidade de São Paulo (USP), instituição que na época, se encarregou da formação em nível superior do professorado indígena do Estado de São Paulo, ainda lutam para que a Escola Ekeruá também ofereça o Ensino Médio, de modo a garantir que os/as estudantes indígenas concluam a Educação Básica na Aldeia.

Os/as adolescentes, após o Ensino Fundamental todo realizado em Ekeruá, quando saem para cursar o Ensino Médio nas escolas não indígenas, enfrentam muitos percalços para a conclusão da Educação Básica, pois não veem sentido no que lhes é ensinado nestas escolas, cujos conhecimentos compartimentados e a convivência fragmentada, não correspondem à sua realidade. E, somado ao preconceito e discriminação que sofrem, acabam por se sentirem mais prestigiados e prioritários na aldeia, contribuindo com os projetos ali desenvolvidos e que participaram da construção. Em razão da defasagem destas Escolas em relação aos estudantes indígenas (e não o contrário!), a evasão é recorrente e a conclusão da Educação Básica sai do horizonte de possibilidades desses jovens.

Outra importante característica identificada na escola e na comunidade é a valorização do coletivo, da convivência entre crianças, adolescentes, professores/as e familiares. A participação na vida comunitária e a convivência são aspectos marcantes dos modos de educar Terena, como também observou Novais (2013, p. 136-137) em 
seu estudo na Aldeia Terena da Terra Indígena Taunay/Ipegue no Estado do Mato Grosso do Sul:

\begin{abstract}
Envolvidos em um conjunto de práticas sociais, os Terena se educam no dia a dia de suas aldeias por meio da demonstração feita pelos mais velhos às crianças, que estão sempre juntas de seus pais e avós. E assim, brincando de imitar as atividades feitas por eles, ouvindo as histórias, cuidando da roça e participando dos rituais, vão aprendendo sem pressa, medo ou castigo, até acertar. Integradas na vida comunitária, as crianças aprendem as regras do jogo social.
\end{abstract}

Em uma das incursões pudemos presenciar o momento em que "[...] todos os professores e todos os alunos estavam juntos [...] iam procurar sementes para fazer colares, como iniciou o mês de abril, todos teriam aula juntos, incluindo as turmas da tarde" (Diário de Campo, 09 de abril de 2012).

No âmbito dos espaços, é difícil fazer uma descrição exata do que é a escola e do que não é, pois as atividades escolares acontecem em vários espaços da Aldeia, possibilitando a construção do conhecimento significativo e não compartimentado do mundo-vida. Presenciamos a interação entre o que as crianças e os adolescentes aprendem na escola com o que vivem em seu cotidiano, por exemplo, quando por ocasião de uma aula do componente curricular Geografia, a professora e os/as educandos/as realizaram uma trilha existente na Aldeia, em que dialogavam o conteúdo específico daquela área de conhecimento, a partir de questões insurgentes do lugar onde vivem e que, eles inclusive, ajudam a cuidar, tornando o conhecimento tratado na Escola mais significativo, pois não desvinculado do seu mundo-vida (Diário de Campo, 17 de agosto de 2011).

Neste sentido Luciano (2011, p. 75-76) menciona que a educação escolar indígena diferenciada deve garantir:

[...] o fortalecimento e a continuidade de saber próprios de cada comunidade indígena e a necessária e desejável complementaridade de conhecimentos científicos e tecnológicos, de acordo com a decisão e vontade de cada povo ou comunidade.

Essa dimensão de complementariedade do saber contrasta com a organização dos conhecimentos na Escola da Aldeia Ekeruá, obedecer ao critério tradicional disciplinar ocidental de ensino compartimentado na "grade curricular", inclusive, com os mesmos componentes curriculares ${ }^{10}$ das escolas não indígenas. Com exceção da aula de Oficina, responsável pela especificidade do ensino indígena Terena, todos os demais componentes curriculares eram orientados pelo Currículo da Secretaria de Estado da Educação de São Paulo (SÃO PAULO, 2011).

Esses contrastes, longe de significarem um problema para eles, são desafios que se superam com o comprometimento com o ato de ensinar e com a sabedoria em se apropriar do conhecimento científico ocidental sem abandonar seus referenciais:

[...] eles seguem o caderno do Estado, mas têm que fazer adaptações do conteúdo presente, pois muitos dos exemplos que constam no caderno não fazem parte do cotidiano das crianças [...] Para trabalhar o metro, ensinar distância, confecciona com os alunos o arco e a flecha, os alunos brincam

10 Os componentes curriculares correspondiam a: Língua Portuguesa, Língua Inglesa, Ciências, Matemática, Educação Artística, Educação Física, Geografia, História e Oficina. Esta última é dedicada ao estudo do idioma Terena, das histórias, das danças, dos rituais e de outros elementos da cultura Terena. 
com o material e depois medem a distância que flecha atingiu; e por meio do tiro ao alvo (zarabatana) ensina as cores no idioma Terena (Diário de Campo, 17 de agosto de 2011).

Salientamos que os Terenas têm um modo próprio de trabalhar com cálculos, aplicado nas atividades do cotidiano, na colheita e no trabalho de coleta na mata, cuja base é três. Assim, como a aldeia é formada por três gerações (velhos, adultos e crianças), o mundo em três grupos (Terenas, outros povos e os não indígenas) os produtos coletados na mata e a colheita são reunidos em três partes: um para consumirem entre os familiares; outro para dividir com amigos e parentes e outro para vender (NOVAIS, 2013).

A questão é que por não terem sido contemplados com um Currículo que se orientasse pelos saberes e necessidades da comunidade Ekeruá e que tivesse como referência o mundo-vida Terena, os obrigava a todo o momento a se anteciparem em produzir estratégias para dominar os conhecimentos científicos escolarizados, sem subverter, hierarquizar ou mesmo suprimir seus saberes, para atingirem os fins e propósitos embutidos no "currículo oficial".

Concordamos com D'Angelis (2001, p. 37) quando diz que "[...] a escola em uma sociedade indígena não é - ou, pelo menos, não deveria ser - igual à escola da sociedade brasileira não-indígena, exatamente porque os valores e as necessidades educacionais da sociedade indígena são diferentes".

Há, portanto, um esforço contínuo dos/as professores/as, bem como do vicediretor da escola, em manter as manifestações da cultura Terena presentes também enquanto conteúdos que perpassam todos os componentes curriculares. As aulas de Oficina, embora sejam destinadas ao aprofundamento do estudo da língua materna, e também, para cultivarem os ritos e tradições a partir das manifestações próprias de seu povo, não são exclusivas para abordagem de tais conhecimentos.

Conhecemos muitas brincadeiras ensinadas pelas crianças, cujas manifestações lúdicas, especificamente jogos e brincadeiras, diferente da escola não indígena e, inclusive, como prevê o Currículo do Estado de São Paulo, não está restrito a um ou dois componentes curriculares específicos, no caso a Educação Física, e por vezes, a Arte.

Há uma simbologia da cosmovisão Terena fortemente presente nas histórias e também em outra brincadeira que vivenciamos, chamada pela comunidade por brincadeira da "Ema", descrita a seguir:

\footnotetext{
De mãos dadas, todos formam um semicírculo, exceto quem será a Ema. O semicírculo formado representa uma armadilha que deverá capturar a Ema, mas para que ela fique presa, todos devem estar em silêncio, pois se a Ema ouvir qualquer barulho ela se assusta e foge. Quando a Ema entrar, todos devem formar uma roda rapidamente, unindo as duas pontas do semicírculo e prendendo a Ema dentro dela. Quando presa, a Ema pergunta no idioma Terena para cada um da roda "Kuti itukovo tikotirá?" (em português - "Qual árvore é você?”) e um por um vão respondendo (Ipê, Pau-Brasil, Jequitibá etc.). Depois disso, a Ema tem que escapar e para isso ela sai correndo, forçando a roda até duas pessoas soltarem as mãos e então quando consegue sair, todos vão atrás dela e quem a pegar será a próxima Ema (Diário de Campo, 17 de agosto de 2011).
}

A Ema é um animal sagrado para os Terena, homenageado na dança realizada pelos homens conhecida como "Kipâe" ou dança do "Bate-pau". Podemos identificar tal fato no seguinte trecho do diário de campo: 
[...] existiam muitos conflitos com outras etnias antigamente, pois eles não se entendiam, não falavam a mesma língua. Foi aí que surgiu a dança conhecida como "Kipâe" (em português significa Ema), símbolo da guerra e vitória dos Terenas, é a mesma dança do bate-pau. O professor de oficina contou que "É uma dança lenta no começo, com um passo em cima do outro, para não chamar a atenção dos inimigos", tem o nome de Ema, pois usavam a pena desse animal na dança "Pra gente a Ema sempre foi sagrada" [...] Hoje, não usam mais a pena de Ema, pois não tem em Ekeruá, mas segundo o professor de oficina, "A Ema está viva no céu, a noite eu consigo ver" (Diário de Campo, 14 de maio de 2012).

Todos esses conhecimentos e modo de educar fazem parte de um todo social, não passível de rupturas, que extrapola a "grade curricular" e o ensino escolarizado, o que nos remete a questionamentos acerca de qual educação intercultural estamos a construir.

\section{CONSIDERAÇõES TRANSITÓRIAS}

A convivência com a comunidade indígena Ekeruá, permitiu-nos confrontar experiências e saberes e refletir acerca de pré-concepções acerca da educação indígena e da escola neste cenário. Neste sentido, se faz jus rever nossas questões de partida para a investigação assim como abraçar novos questionamentos que resultaram da interação com a comunidade.

Neste percurso, aprendemos o olhar cuidadoso para aquilo que se chama e se proclama como educação intercultural, especialmente se tratando do conhecimento indígena em um espaço institucional e eurocentrado que é a Escola.

As lentes pelas quais olhamos o fenômeno deve possibilitar compreendê-lo em diferentes ângulos, onde aquele com maior amplitude nos chama a atenção para primeiro: estarmos alertas com a educação intercultural tomada pela colonialidade do poder como uma forma de opressão e assimilação dos povos indígenas, como denunciado por Menares (2014) e Pérez (2014); e segundo, para as ambiguidades inerentes ao processo histórico de acesso, apropriação e inserção da Escola nas comunidades indígenas. Ao diminuirmos a amplitude lançamos o foco ao contexto a partir do qual emergiram nossas reflexões, que neste caso, se trata da comunidade indígena Terena Ekeruá, a qual nos alerta para aquilo que é particular: seus anseios, receios, preocupações expectativas e perspectivas que permeiam os processos educativos no interior da Escola da Aldeia Ekeruá.

O movimento das lentes possibilita refletir que no contexto da Aldeia Ekeruá, cuja existência se dá pela relação cotidiana com a sociedade não indígena, em uma região urbana altamente adensada, a Escola é lócus de preservação identitária Terena: de sua língua materna, de suas histórias, de suas danças, de seus jogos, de seus rituais e é também um espaço importante de apropriação da perspectiva de conhecimento ocidental e de obtenção de instrumentos para a leitura desta outra epistemologia. Assim, na imbricada e tensa rede de relações que tecem cotidianamente com a sociedade e o conhecimento ocidental, a escola é o lugar no qual tais conhecimentos são ressignificados a partir da epistemologia indígena Terena, é, portanto, tempo-espaço de interconhecimento, de educação intercultural.

Cabe salientar que a interculturalidade que defendemos rompe com a hierarquia de conhecimentos e assume a premissa da Ecologia dos Saberes, na qual o conhecimento é concebido como um sistema aberto e interdependente em constante criação e renovação, portanto: 
[...] cruzam-se conhecimentos e, portanto, também ignorâncias [...] a ignorância não é necessariamente m estado original ou ponto de partida. Pode resultar de esquecimentos ou desaprendizagem implícitos nas aprendizagens recíprocas através das quais se realiza a interdependência (SANTOS, 2010, p. 157).

A luta pela educação intercultural deve ser uma luta de todos e todas, no sentido de transpor o desperdício de experiências e conhecimentos dos povos indígenas, que se traduz na discriminação e no preconceito que sofrem cotidianamente. É uma luta solidária, jamais solitária, e traz a tona processos educativos próprios dos povos indígenas que foram obscurecidos, silenciados e invisibilizados.

É preciso nos voltar ao que nos ensinou a convivência na comunidade Ekeruá: aprender a fazer da escola um lugar de partilha; de não fragmentação dos tempos e espaços; de aprender mais do que ensinar; de ouvir mais do que falar e de não termos medo de compartilhar nossos saberes e ignorâncias, enfim, estarmos abertos ao diálogo do encontro olho no olho e receber do outro o que ele pode nos oferecer, pois:

A ignorância é só uma forma desqualificada de ser e de fazer quando o que se aprende vale mais que o que se esquece. A utopia do interconhecimento é aprender outros conhecimentos sem esquecer os próprios (SANTOS, 2010, p. 157).

\section{REFERÊNCIAS}

ANDRÉ, M. E. D. A. Etnografia da prática escolar. Campinas: Papirus, 1995.

BENITES, T. A escola na ótica dos Ava Kaiowá: impactos e interpretações indígenas. 2009. Dissertação (Mestrado em Antropologia Social) - Universidade Federal do Rio de Janeiro, Rio de Janeiro, 2009.

BOGDAN, R.; BIKLEN, S. K. Notas de campo. In: BOGDAN, R.; BIKLEN, S. K. Investigação qualitativa em educação: uma introdução à teoria e aos métodos. Porto: Porto Editora, 1994. p. 150-175.

BRASIL. Ministério da Educação e do Desporto. Secretaria de Educação Fundamental. Referencial curricular nacional para as escolas indígenas. Brasília: MEC/SEF, 1998.

D'ANGELIS, W. R. A educação escolar em novos contextos políticos e culturais. In: VEIGA, J.; SALANOVA, A. (Org.). Questões de educação escolar indígena: da formação do professor ao projeto de escola. Brasília: FUNAI/DEDOC; Campinas: ALB, 2001. p. 35-56.

FERNANDES, R. F. Educação escolar Kyikatêjê: novos caminhos para ensinar e aprender. 2010. Dissertação (Mestrado em Direito) - Universidade Federal do Pará, Belém, 2010.

GONÇALVES JUNIOR, L. Etnomotricidade: multiculturalismo e educação física escolar. In: CORREIA, W. R.; CARREIRA FILHO, D. (Org.). Educação Física Escolar: docência e cotidiano. Curitiba: Editora CRV, 2010. p. 49-67.

ISA. Instituto Socioambiental. Terena: localização e população. Povos indígenas no Brasil, ISA, 2014. Disponível em: < https://pib.socioambiental.org/pt/Povo:Terena >. Acesso em: 13 jul. 2018.

KRENAK, A. Em busca de uma terra sem tantos males: o Watu, o crime ambiental e a teia da vida. Coimbra: CES/UC, 16 mar. 2016. (Palestra).

LUCIANO, G. S. Educação para manejo e domesticação do mundo: entre a escola ideal e a escola real - Os dilemas da educação escolar indígena no Alto Rio Negro. 2011. Tese (Doutorado em Antropologia Social) - Universidade de Brasília, Brasília, 2011. 
Denise A. Corrêa; Fernanda Z. Arthuso

LUCIANO, G. S. O índio brasileiro: o que você precisa saber sobre os povos indígenas no Brasil de hoje. Brasília: MEC/SECAD; LACED/Museu Nacional, 2006.

MENARES, G. P. ¿Cómo descolonizar el saber? El problema del concepto de interculturalidad: reflexiones para el caso mapuche. Polis Revista Latinoamericana, v. 13, n. 38, p. 205-223, 2014.

MUNDURUKU, D. Cultura indígena e suas contribuições para o desenvolvimento humano. Bauru: SESC, 22 mar. 2013. (Palestra).

NOVAIS, S. N. S. Prática social de ressignificação da educação escolar indígena: compreendendo os processos educativos do cotidiano Terena do município de Aquidauana-MS. 2013. Tese (Doutorado em Educação) - Universidade Federal de São Carlos, São Carlos, 2013.

PÉREZ, A. Z. Interculturalidad y decolonialidad. Tabula Rasa, v. 20, p. 91-107, ene.-jun. 2014.

QUIJANO, A. Colonialidade do poder e classificação social. In: SANTOS, B. S.; MENESES, M. P. (Org.). Epistemologias do sul. São Paulo: Cortez, 2010. p. 31-83.

SANTOS, B. S. A gramática do tempo: para uma nova política. 3. ed. São Paulo: Cortez, 2010.

SANTOS, B. S.; MENESES, M. P. Introdução. In: SANTOS, B. S.; MENESES, M. P. (Org.). Epistemologias do sul. São Paulo: Cortez, 2010. p. 15-27.

SÃO PAUlO (Estado). Secretaria da Educação. Currículo do Estado de São Paulo. 2. ed. São Paulo: SE, 2011.

WILL, K. L. P. Genocídio indígena no Brasil. 2014. Dissertação (Mestrado em Ciências JurídicoPolíticas) - Universidade de Coimbra, Coimbra, 2014.

Recebido em: 13 jul. 2018.

Aprovado em: 26 jul. 2018. 